\title{
Aprendizaje de \\ la lectoescritura \\ en un contexto \\ intercultural en la \\ educación infantil
}

María Soledad Martínez Gámez

Maestra de Educación Infantil en el CEIP "Pintor Eduardo Morillas"

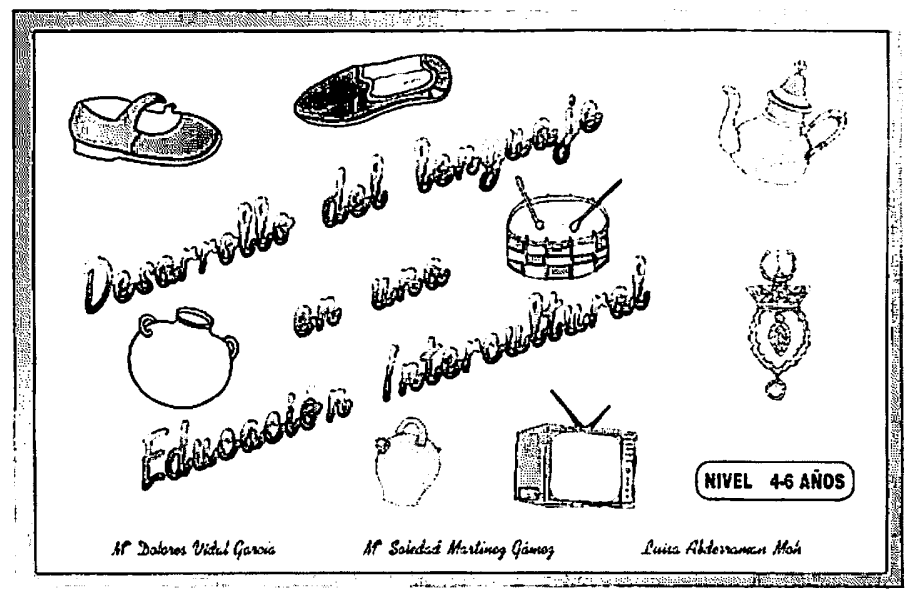

Figura 1

Portada de la publicación

\section{Introducción}

La presente conferencia tiene por objeto dar a conocer una experiencia de trabajo realizada en el C.E.I.P. Mediterráneo durante el periodo 1991-1995. Un grupo de maestras de Educación infantil decidimos iniciar la aplicación de un método de aprendizaje de la lectoescritura, al objeto de dar respuesta a las necesidades especificas del alumnado. Fruto de esta experiencia surgieron materiales, fichas de trabajo y actividades que afectaron a todo el currículum. El entonces Ministerio de Educación y Ciencia publicó en 1995 la obra "Desarrollo del lenguaje en una Educación infantil" con la finalidad de acercar esta experiencia educativa al resto de Centros con niños y niñas de cultura y lengua materna tamazight. Es necesario transmitir al colectivo de maestros-as la ilusión por la innovación y el desarrollo de nuevas ideas con el solo objeto de trabajar por el mejor desarrollo educativo del alumnado. 


\section{Consideraciones previas a la enseñanza de la Lecto escritura}

En el momento de trabajar en el ámbito del aprendizaje y desarrollo del lenguaje oral, con niños y niñas de cultura y lengua materna tamazight, surgen una serie de necesidades específicas dado que presentan rasgos fonológicos, morfológicos y sintácticos diferentes al hispano parlante. Esto implica que los niños-as empiezan su experiencia escolar con un nulo o escaso conocimiento de la lengua dominante propia del contexto escolar, implicando una desventaja que el educador debe mitigar.

Cuando un grupo de maestras pretendimos emprender el aprendizaje de la lecto escritura con este tipo de alumnado, comprobamos que los textos existentes en el mercado no respondian a las necesidades reales del mismo, aumentando si cabe la desventaja inicial. Los textos existentes no tenían en cuenta la ordenación de las vocales y consonantes, dándose el caso de "cartillas" que comenzaban con el fonema " $r$ " de muy difícil pronunciación para estos niños. El fonema " $r$ " es habitualmente confundido con el $n^{0} 2$ invertido. Otras "cartillas" o libros de lectura contenían palabras que no eran significativas para los niños tales como "rae", "roe", "duelo"...........

Una vez que analizamos todos los textos a nuestro alcance, decidimos elaborar nuestros propios materiales ajustándonos a las necesidades de nuestros alumnos-as, naciendo lo que en un principio se llamó proyecto "Aurín", configurando poco a poco un libro de trabajo, al que posteriormente se le incluyó un fundamento teórico que le aportase rigor, así como los criterios de ordenación de los fonemas razonados y experimentados.

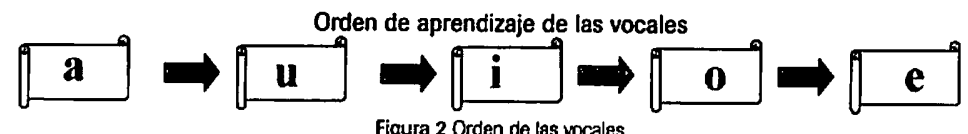

El orden de aprendizaje de las vocales arriba indicado obedece a que en lengua Tamazight no existe una oposición clara entre los fonemas "i"/ "e". Los alumnos-as confunden estos dos sonidos. Ejemplos: "misa"-"mesa" "huivu"-"huevo" “pilota"-"pelota". En el orden de aprendizaje de las consonantes también se ha seguido un orden bajo el criterio de oposición fonética, teniendo en cuenta además que existen sonidos consonánticos en español que no están presentes en la lengua tamazight y viceversa. Otros fonemas consonánticos resultan dificultosos en pronunciación y articulación. De este modo es necesario un tratamiento especial a nivel articulatorio de los siguientes fonemas: " $p$ " " $b$ " " $h$ " “ $z$ " "ñ" "s".

- El fonema /p/ introducido por prestamos, sustituyendo en algunas palabras el fone$\mathrm{ma} / \mathrm{b} /$

- Aspiración de la /h/ en los nombres propios. Ejemplo: Mohamed

- El fonema $/ \tilde{n} /$ equivale a $/ \mathrm{n} / \mathrm{t} / \mathrm{i} /$

- Diferentes sonidos para los fonemas $/ z / y / s /$ 
Las fichas de trabajo realizadas están orientadas para alumnos-as de 4 a 7 años, abarcando Educación Infantil y $1^{\circ}$ de Educación Primaria. Las fichas están concebidas como actividades terminales, nunca como contenidos de trabajos en si mismas y podemos calificar dicho proceso de analítico-sintético.

Se parte de la palabra por ser ésta más significativa para el niño. Esta palabra, surge en la Asamblea o bien observando una lámina o foto. Más tarde esta palabra-clave se descompone en silabas y posteriormente el niño descubre el fonema a trabajar. El orden de presentación se ha hecho atendiendo al grado de dificultad de los sonidos (tal y como se ha expuesto anteriormente) y se trabaja simultáneamente la lectura y la escritura. La elección de las palabras se ha realizado teniendo en cuenta la importancia del conocimiento previo. Sus nombres, palabras comunes a su entorno y comunes tanto en la cultura Tamazight como española que nos enriquecen y que nos permiten ampliar las informaciones socioculturales del ambiente.

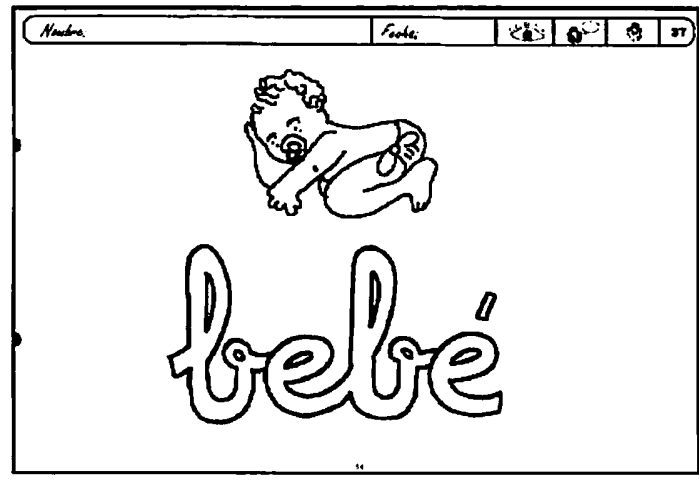

Ejemplo de palabra clave

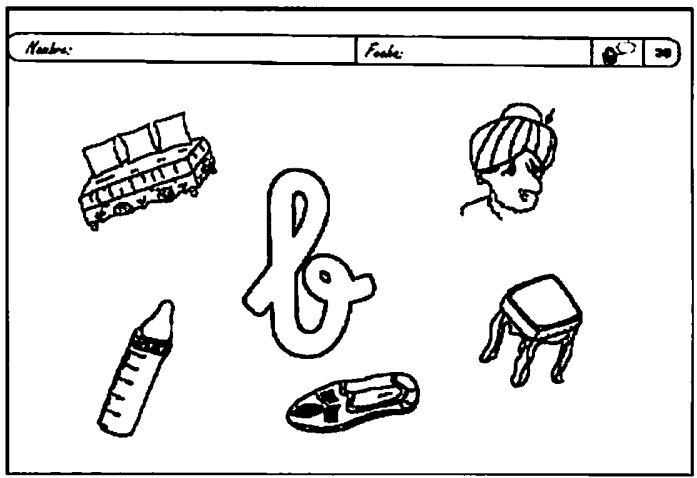

Ejemplo de vocabulario 


\section{Importancia del lenguaje oral}

La importancia del lenguaje oral es importantísima y previa a todas las actividades de lecto-escritura. Obviamente el lenguaje oral es previo al lenguaje escrito, los niños y niñas llegan a la escuela con un lenguaje en Español muy limitado y habiendo desarrollado conceptos y nombres que son únicos en su lengua. También es frecuente el caso de alumnos-as que conviven con padres y familiares monolingües en lengua Tamazight. De este modo al ser el lenguaje oral un lenguaje anterior al escrito, se encuentra íntimamente ligado al pensamiento. En la etapa de educación infantil el lenguaje oral ocupa la mayor parte del tiempo escolar. Su desarrollo se convierte en prioritario, pues este constituye el principal y a veces el único medio de comunicación y cultura.

Las actividades de desarrollo del lenguaje oral comienzan trabajando las capacidades previas, formadas por los ejercicios de:

- Respiración: Inspiración-expiración, emitiendo diferentes sonidos. Soplado de globos, juegos con cañitas, soplado de papeles de diferentes texturas, juegos con agua y jabón......

- Ejercicios de fonoarticulación: Con movimientos de lengua, mandíbulas y labios. Supone un desarrollo y ejercitación de los órganos del ser humano que intervienen en el lenguaje.

- Audición:Percepción de silencio-ruido-sonido, condición de diferentes sonidos/ruidos, reproducción de sonidos.

- Expresión: Expresión libre y dirigida, juegos de imitación, juegos de dramatización, juego del veo-veo.

Es importante para llevar a cabo la Expresión oral, crear un espacio que favorezca el intercambio. Los niños-as se sientan en la alfombra viéndose todos cuando hablamos. Los niños expresan sus experiencias tanto en lengua materna como en español, favoreciendo el bilingüismo. Por ello es importante que el docente tenga un conocimiento del vocabulario Tamazight mínimo y agrupado en campos semánticos y apoyados en imágenes, fotos, láminas, etc.......

También es necesario ofrecer un modelo de lenguaje rico y correcto, ya que la competencia lingüística del niño depende de la calidad del lenguaje que escucha a su alrededor. Es necesario establecer una función compensatoria de carácter individual. Por último, es necesario añadir que debemos escuchar a cada niño y conversar con él, al objeto de poder conocer su propio estadio psico-lingüístico.

¿Cuando realizar las actividades del lenguaje oral? siempre. Es necesario verbalizar todas las actividades.

La pretensión del docente no es solo lograr que el niño hable sino crear situaciones que estimulen y motiven al niño en torno a temas de interés para ellos, organizando dichos temas en Unidades Didácticas y elaborando muestras fichas, vocabulario y carteles atendiendo a la multiculturalidad. Este método genera un clima de confianza y afecto en el que el niño experimenta la necesidad y la satisfacción de comunicarse. 
Aprendizaje de la lectoescritura en un contexto intercultural en la educación infantil

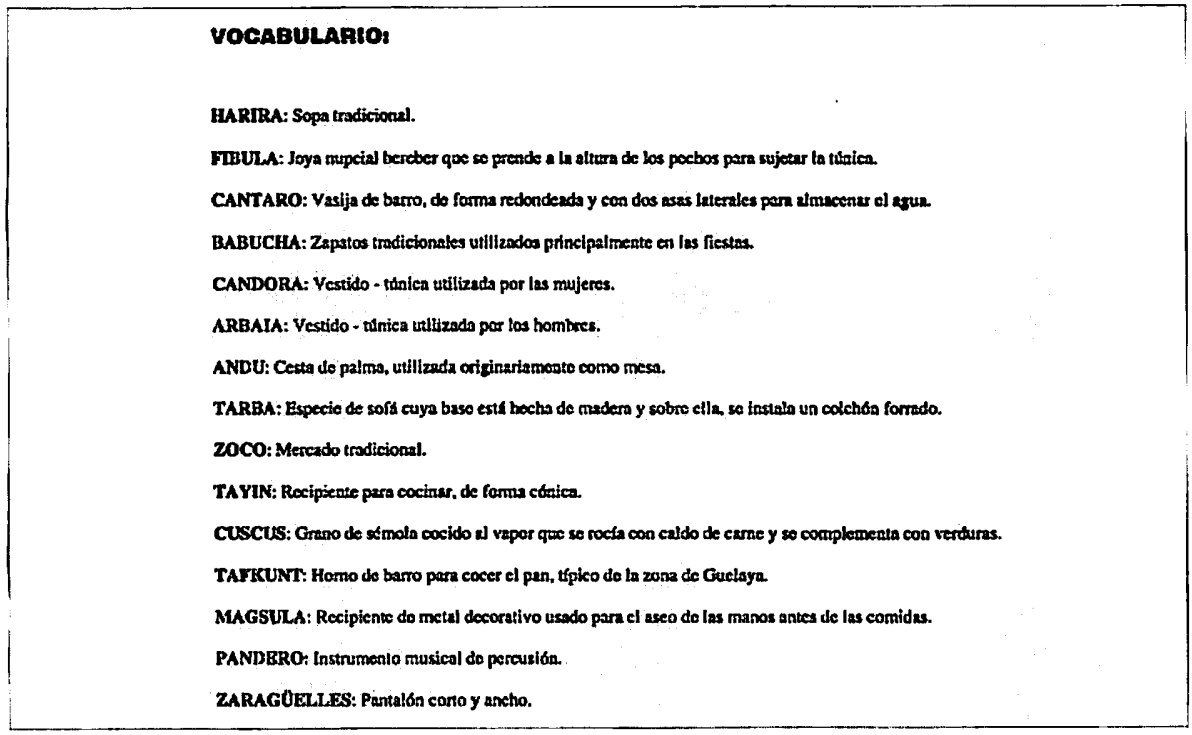

Figura 4 Ficha de vocabulario Tamazight 
Coleglo:

Cunta:

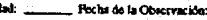

DEXARROLLO DEL IENGENR

A. CAPACIBADES FREVIASAR LENGUNGEORAL.

I. Es rxpux de soptior

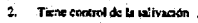

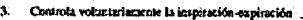

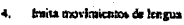

5. Interna roprodixis palation

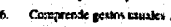

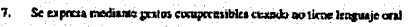

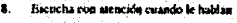

9. Laita xonidas voclison

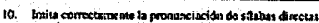

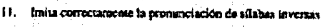

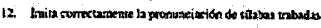

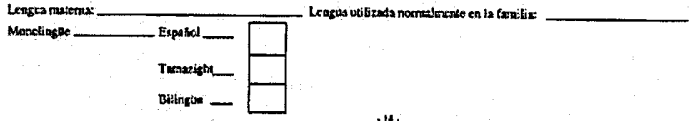

.14.

\section{E MVEL,ASTICUIATORIO}

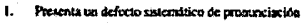

2. Iovicerto bet nuthax

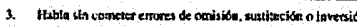

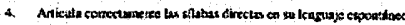

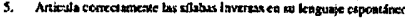

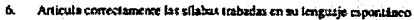

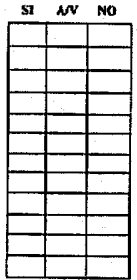

c. Nivil. SintAcrico

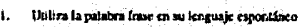

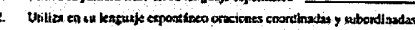

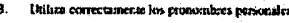

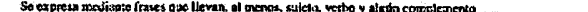

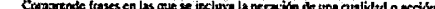

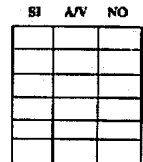

Observectionos:

1. NTYEL cosgracatrvo

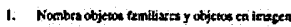

2. Sabe docti sa nontibe $y$ apellutos

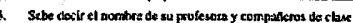

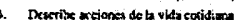

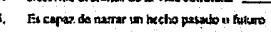

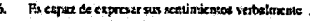

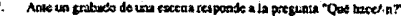

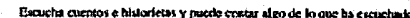

Se apoye en iztor

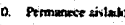

11. Le grusu coonsunicar

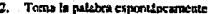

13. Sabe exwechar

14. Tene en cuencis lo que ficeri kas derets

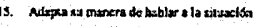

16. hegatesnel katasisic

Omermacinat:
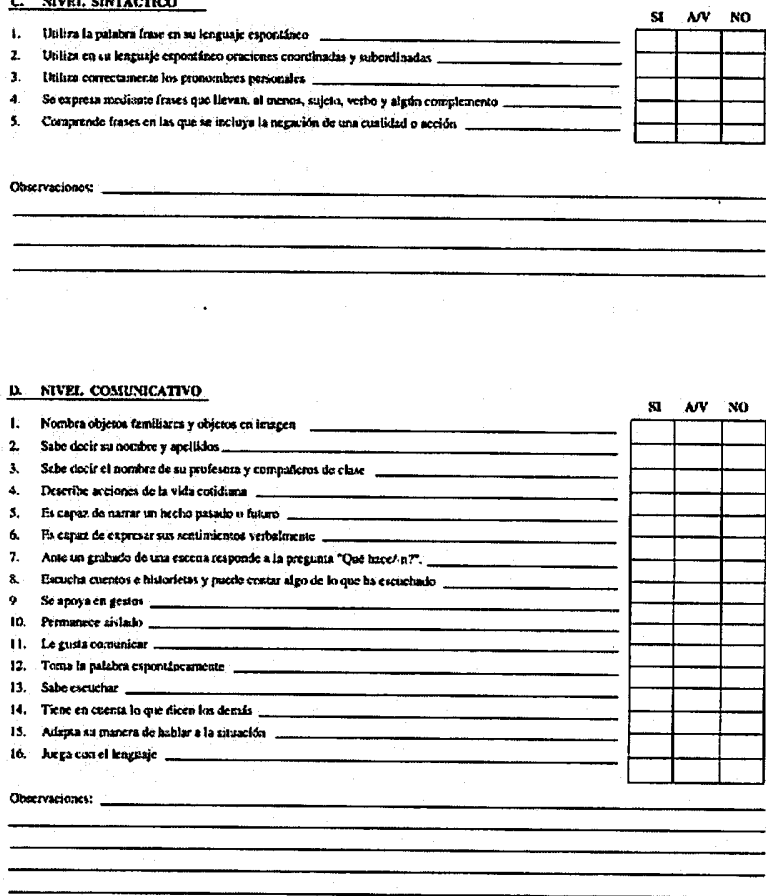


\section{El aprendizaje del lenguaje escrito}

El aprendizaje del lenguaje escrito, está intimamente ligado al aprendizaje del lenguaje oral. Durante el desarrollo en el aula del lenguaje oral, todo el aprendizaje se traslada a nivel gráfico. Cuando los niños hablan sobre algo que vieron hicieron o elaboraron, escribimos lo que dicen exactamente y luego se lo leemos, de tal forma que atestiguan la escritura y la lectura de sus propias ideas. Aprenden a que pueden hablar de sus propios pensamientos, sentimientos e ideas. De este modo comprueban que lo que hablan puede ser escrito. Esta técnica les anima al aprendizaje de la lecto escritura ya que supone un estimulo positivo. Veamos un ejemplo:

- En primer lugar se procede a la lectura de un cuento.

- El niño realiza un dibujo donde expresa lo que mas le ha gustado de él, los diferentes personajes y las escenas que más le han impactado.

- El niño/a explica a la maestra lo que ha dibujado. Ésta toma anotaciones en el dibujo de la explicación del niño.

- De esta manera se componen nuestros propios cuentos que quedan en el aula para que los niños lo puedan leer.

- Este mismo procedimiento se emplea a través del dibujo libre, con ocasión de visitas que el aula realiza a lugares de interés y en la celebración de determinadas fiestas.

\section{Proceso del aprendizaje de la escritura}

La escritura se debe considerar como el desarrollo de un proceso grafomotor, de ahí la importancia del desarrollo de las capacidades previas, que serían:

- La Psicomotricidad: Realización de actividades que impliquen el movimiento del cuerpo, estimulando la habilidad de correr, saltar

- La Grafomotricidad: Se realiza teniendo en cuenta de forma primordial los elementos grafomotores, que hacen posible el proceso madurativo del niño.

Los elementos grafomotores tenidos en cuenta son:

a) El niño/a: Es el elemento básico, sin él no existe la escritura.

b) El soporte y la posición: Estos dos elementos, que no pueden ir separados, están intimamente ligados al niño/a. El soporte se constituye en el elemento receptor de la actividad grafomotriz. La pared, el suelo, papel continuo, papel DIN-A3, DIN-A4 y papel pautado son los diferentes soportes utilizados en el aula y se encuentran ordenados por orden de utilización.

En lo referente a la posición puede ser: horizontal-horizontal. El niño/a dibuja-garabatea en el suelo y tumbado. Vertical-vertical El niño realiza su producción grafomotriz sobre la pared y de pie. primero utiliza el papel continuo para disminuir progresivamente el tamaño del soporte a través de la pizarra, posteriormente una cartulina y así se establece un mecanismo de inhibición, creando unos limites que el niño/a no puede sobrepasar. También se considera que el soporte vertical regula la independencia seg- 
Marla Soledad Martínez Gámez

Visita al gimnasio os tov as mariem
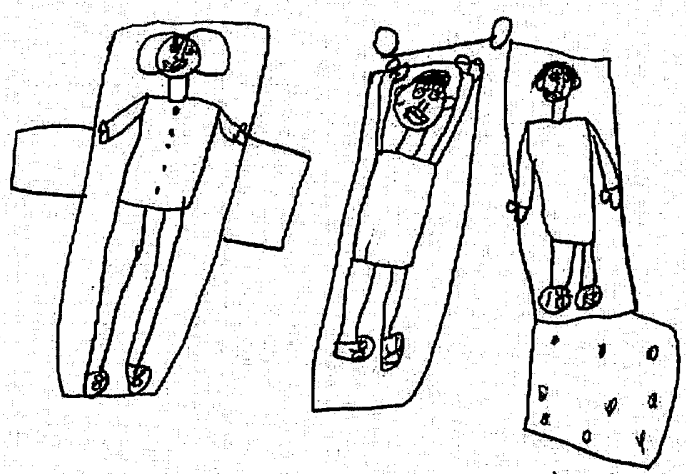

el hombre del gimnario sulievdo y bajondo las pienuas

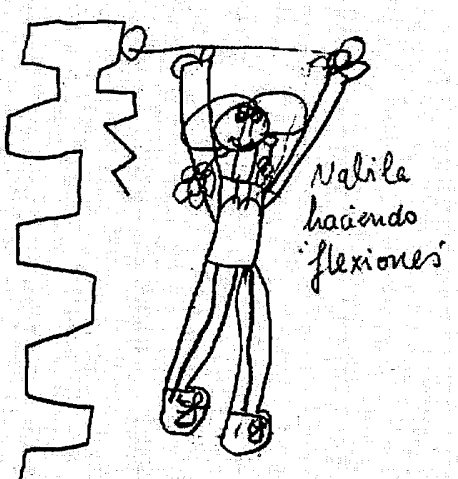

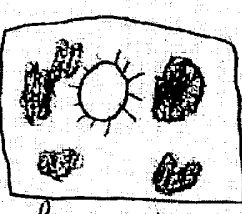

Hoy hemes hecho datiles con almendras biOla. 2. Feh. 96

la ventana de la clase

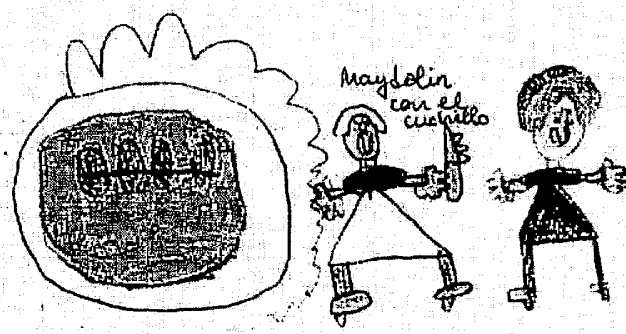

La bandeja de datiles cou almendras

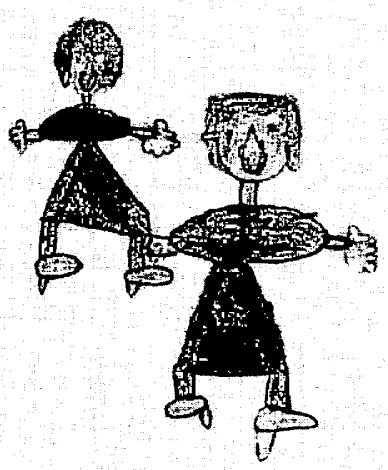

Figura 7 Dibujo realizado por una niña de 5 años, con motivo de celebrar la fiesta de fin de Ramadán

(160) 
mentaria del hombro. Soporte horizontal-posición sedente sobre la mesa. El niño ya está preparado para sentarse a escribir.

c) Los instrumentos: A mayor número de instrumentos utilizados, mayor número de posibilidades. Estos instrumentos no se deben de introducir de forma arbritaria. Los instrumentos se pueden clasificar en naturales y artificiales.

Los instrumentos naturales son aquellos que pertenecen al propio cuerpo del niño/a. Su uso debe establecerse por este orden: manos del niño-dedos del niño-pies del niño. Los instrumentos artificiales son los que permiten el grafismo propiamente dicho. Entre ellos podemos distinguir varias clases que se corresponden a los pasos que hay que seguir en su utilización. Así tenemos:

- Instrumentos que son prolongación de la mano del niño/a y cuya prensión puede ser simplemente palmar: Esponjas, algodones, muñequillas de tela.

- Instrumentos que exigen una prensión radio-palmar: Brochas y pinceles.

- Instrumentos que requieren una prensión digital: Tizas, tampones

- Instrumentos que trabajan la prensión digital de índice-pulgar-medio: Punzones $y$ tijeras.

- Instrumentos que exigen la prensión de pinza-digital: Ceras blandas y duras, rotuladores y lápiz blando $n^{\circ} 2$.

La Graduación de estos instrumentos y la asimilación de las posibilidades que ofrecen cada uno de ellos, crea reflejos neuromotores que se transforman en habituaciones grafomotoras.

d) Los trazos grafomotores:

Los trazos utilizados son los siguientes:

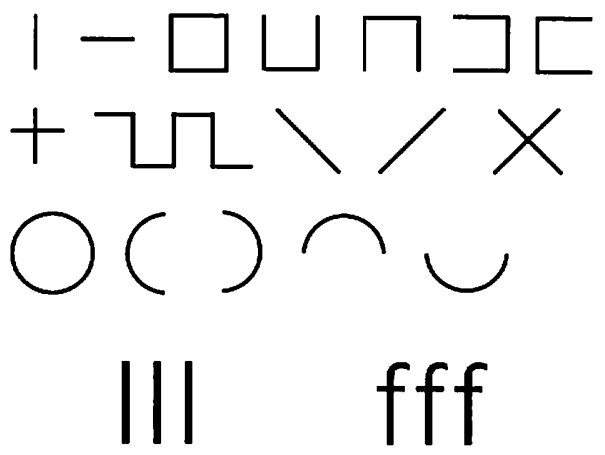

Estos grafos grafomotores se trabajan mediante un proceso de aprendizaje significativo. Veamos un ejemplo:

GRAFIA: 
- Estadio manipulativo vivencial: Observar el agua cuando cae. Podemos utilizar una regadera en el jardín del Centro y observar la trayectoria de las pequeñas gotas. El agua cae de arriba hacia abajo. También podemos aprovechar un día de lluvia y hacerles fijar como cae la lluvia desde las nubes al suelo.

- Estadio de simbolización: Vivir la caida del agua con el cuerpo.

- Estadio de esquematización: Representar plásticamente los hechos observados, dibujando libremente la lluvia, la tormenta, regado de plantas..... También podemos realizar un mural colectivo con pintura al dedo que represente las gotas de lluvia que caen de las nubes.

- Estadio de conceptualización: Realizar en papel la ficha de la lluvia cayendo. También la realizaremos en la pizarra y el muro. Por último la realizamos en el folio.

Una vez abordado el tema de los elementos grafomotores, debemos hacer incapie en las habilidades grafomotoras. Las habilidades grafomotoras trabajadas son:

- Adiestramiento de las yemas de los dedos:

La yema de los dedos son como los ojos de las manos, en ellas se encuentra la mayor sensibilidad digital. Las yemas de los dedos necesitan adiestramiento y fortalecimiento para conseguir una buena sensibilidad. Para ello se realizan ejercicios de modelado, rasgado, recortado con los dedos, repasado de caminos improvisados en la pizarra o en el muro, repasar superficies (trabajando diferentes texturas), realización de bolitas de papel, realización de ejercicios de teclado.

- Aprensión y prensión del instrumento:

Esta habilidad va encaminada a elaborar elementos grafomotores que permiten coger un elemento para manejarlo, asi como dominar el pulso para regular la presión que se ejerce sobre dicho instrumento. Para el desarrollo de esta habilidad existen tres habilidades fundamentales:

- El picado el recortado el cosido

- Dominio de la mano.

Para conseguir esta habilidad desarrollamos actividades de abrir y cerrar cajas, subir y bajar cremalleras, doblar y desdoblar ropa......

- Disociación de ambas manos

- Desinhibición de los dedos

- Separación digital

- Coordinación general de manos y dedos

A modo de conclusión podiamos preguntarnos: ¿Cuándo se trabaja la escritura? La respuesta es sencilla. La escritura se trabaja en la Asamblea, después de la Asamblea, cuando los niños hablan sobre algo que hicieron o nombran palabras que contienen el fonema que nos interesa trabajar. 


\section{Actividades específicas del aula}

Las actividades realizadas en aula son otro de los pilares donde se fomenta la interculturalidad.

- Visitas a lugares del entorno social: Barrio, mercado........

- Visitas a lugares de interés: Cuartel de bomberos, Fabrica de Harinas.........

- Celebración de fiestas: Navidad, Carnaval, Ramadan, del sacrificio......

- Celebración de convivencias: Elaboración del thé, Pastelillos de coco, macedonias de frutas......

La importancia de estas actividades se encuentra en el hecho de que fomentan el conocimiento de un entorno más amplio donde se encuentran otras culturas, reconocimiento del entorno propio en la escuela como factor de integración y el reforzamiento del aprendizaje de la lecto-escritura al favorecer el enriquecimiento del vocabulario y el empleo práctico de la misma. A continuación veremos ejemplos de alguna de estas actividades:
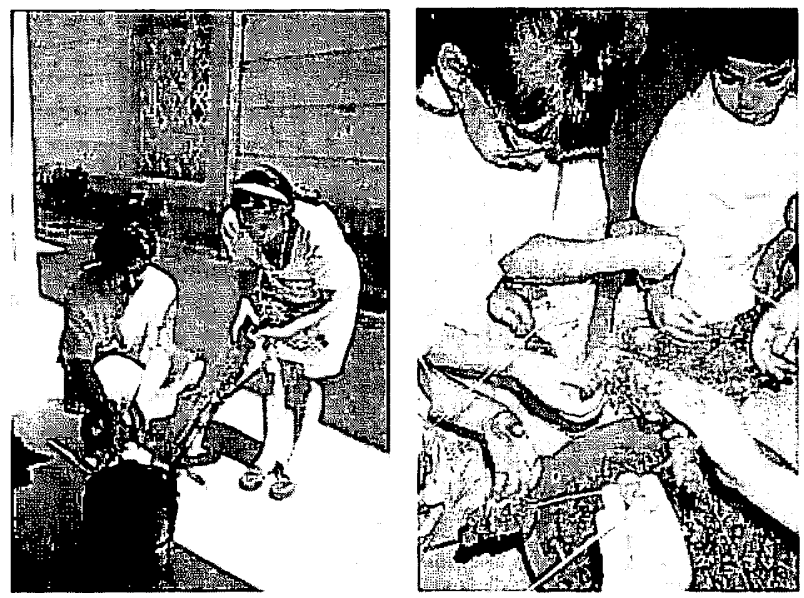

Figuras 8 y 9 Preparación de pinchitos en el aula

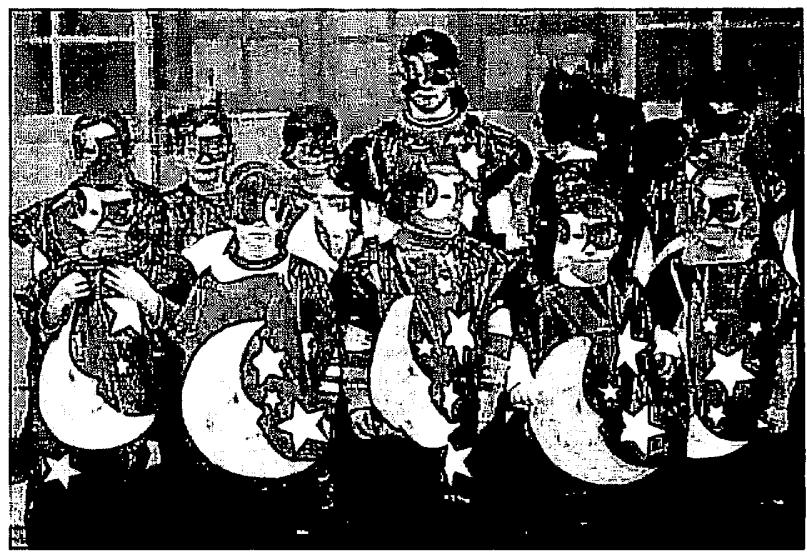




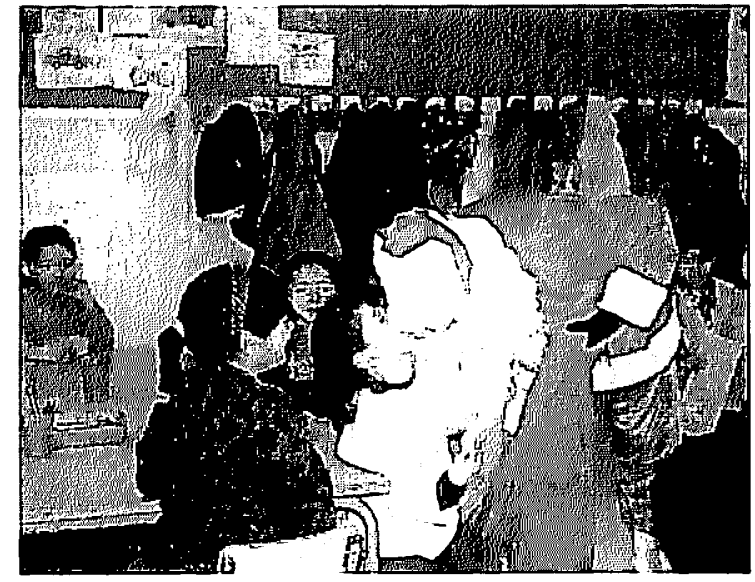

Figura 11 Visita de Papá Nōel

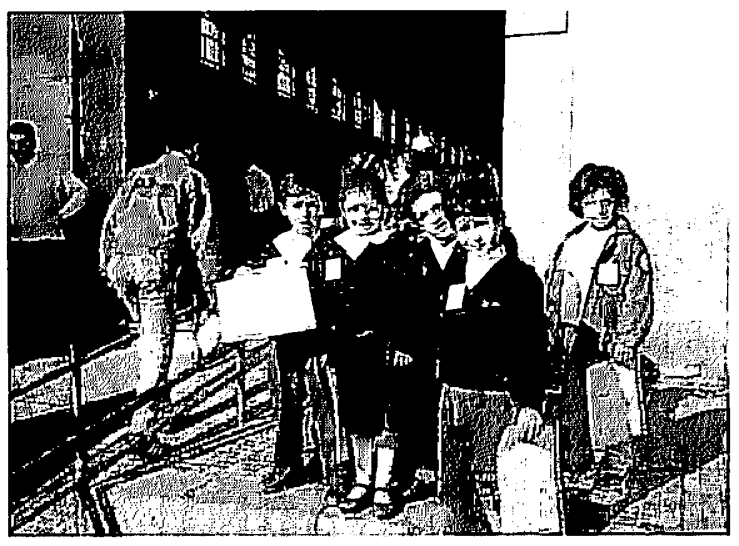

Figura 13 Visita al mercado
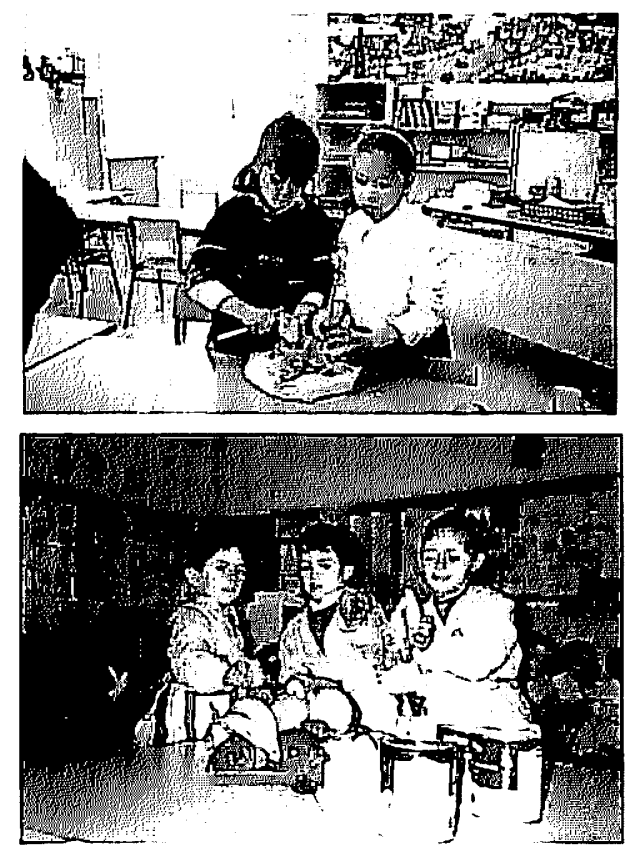

Figuras 12 Elaboración ce una macedonia 


\section{Estructuración de las fichas de trabajo}

Las fichas de trabajo publicadas en nuestro libro, se encuetran secuenciadas de tal modo que al realizar una actividad tipo empezamos con una ficha de lectura, para continuar con fichas de rodeo de silabas, escritura de palabras de dicha silaba, lectura de frases.

Cada ficha lleva en su parte margen superior derecho una serie de pictogramas que facilitan al alumno/a y al profesor el contenido de la actividad propuesta en una ficha concreta.

\section{RELACION DE PICTOGRAMAS:}

Los contenidos que satrabajan están pictografiados de manera que el propio niño puede hacerse consciente de lo que se le pide de una forma visual y concreta y para que el maestrotenga su labar mas fácil al organizar su programación. Cada pietograrma comesponde a un contenido especffico, pero dicho contenido tiene diversas propuestas de deserrollo que consideramos necesarias para la cobertura de los objetivos.

-ESCRIBIR - - -RELACIONATAR

Figura 14 Relación de pictogramas

Complementando a las actividades tipo, disponemos de actividades complementarias a través de fichas que relacionan dibujos y su nombre, completan frases, lectura de una frase y dibujo de lo leido......

No podemos terminar este resumen sin exponer algunos de los dibujos realizados por los niños/as en esta experiencia. 
vilan ari M Ohamed

Mi papá asa pinchitos. wam mi napra asa rinchitos.

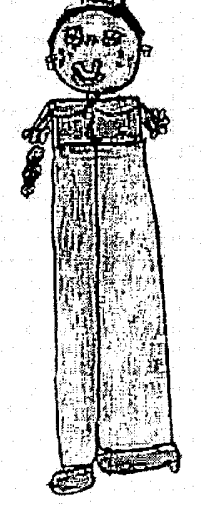

Figura 15 Dibujo de Izlan 5 años

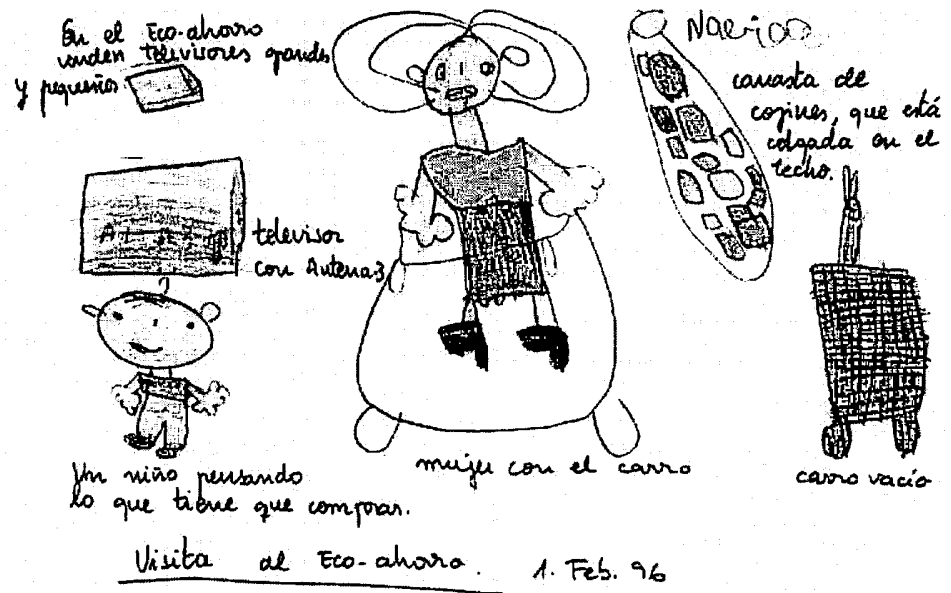

Figura 17 Dibujo de Nabila 5 arios 
Aprendizaje de la lectoescritura en un contexto intercultural en la educación infantil

-

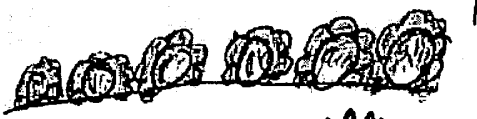

Maydolin

27 HaYO
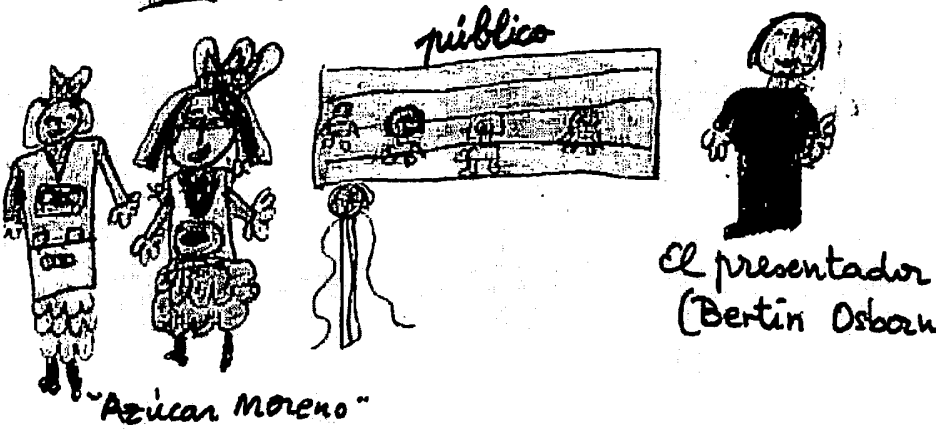
(Bertin Osbouve;
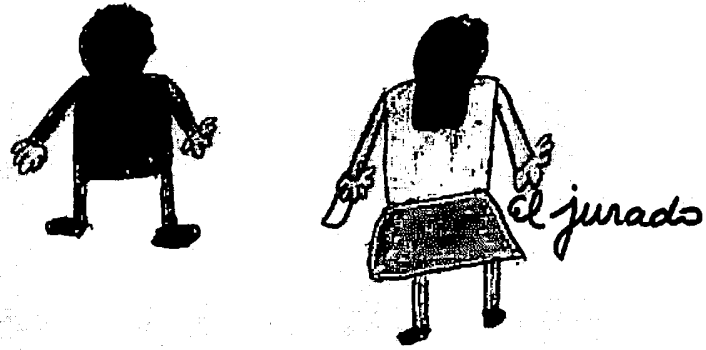

Mi programa favorito de la tele:

"Lluvia de Estrellas

Figura 16 Dibujo de Maydolim 5 años

(167) 